\title{
Targeting TNFR2 in Cancer: All Roads Lead to Rome
}

\author{
Jingchao Bai ${ }^{1,2,3}$, Bowen Ding ${ }^{2,3,4}$ and Hui $\mathrm{Li}^{1,2,3 *}$ \\ 1 Department of Gastrointestinal Cancer Biology, Tianjin Medical University Cancer Institute and Hospital, Tianjin, China, \\ ${ }^{2}$ Key Laboratory of Cancer Immunology and Biotherapy, Tianjin Medical University Cancer Institute and Hospital, Tianjin, \\ China, ${ }^{3}$ National Clinical Research Center for Cancer, Tianjin Medical University Cancer Institute and Hospital, Tianjin, China, \\ ${ }^{4}$ Department of Breast Oncoplastic Surgery, Tianjin Medical University Cancer Institute and Hospital, Tianjin, China
}

TNF receptor 2 (TNFR2) has become one of the best potential immune checkpoints that might be targeted, mainly because of its vital role in tumor microenvironments (TMEs). Overexpression of TNFR2 in some tumor cells and essential function in immunosuppressive cells, especially regulatory T cells (Tregs), makes blocking TNFR2 an excellent strategy in cancer treatment; however, there is evidence showing that activating TNFR2 can also inhibit tumor progression in vivo. In this review, we will discuss drugs that block and activate TNFR2 under clinical trials or preclinical developments up till now. Meanwhile, we summarize and explore the possible mechanisms related to them.

Keywords: TNFR2, Treg, antagonist, agonist, tumor microenvironment

\section{INTRODUCTION}

Escape from the immune system is a well-recognized feature of cancer, which has made immunotherapy the fourth most effective measure in cancer treatment after surgery, chemotherapy, radiotherapy, and targeted therapy. Immune checkpoint inhibitors have sprung up as a mainstream direction. The emergence of monoclonal antibodies (mAbs) against cytotoxic T-lymphocyte-associated antigen 4 (CTLA-4), programmed death 1 receptor (PD-1), and its ligand, PD-L1, has revolutionized the treatment landscape of cancer (1). Improved biomarkers may help to better select patients who are more likely to respond to immunotherapy and benefit new drug development. TNF receptor 2 (TNFR2) has become one of the best potential immune molecules that might be targeted mainly because of its vital role in tumor microenvironments (TMEs) (2).

TME refers to the cellular environment in the tumor site that contains non-malignant cells, tumor-infiltrating immune cells, vessels, intercellular components, metabolites, etc. (3). Recent evidence shows that TME dramatically determines the efficacy of immunotherapy (4). Regulatory $\mathrm{T}$ cells (Tregs) are the most extensively studied immunosuppressive cells; TNFR2 is preferentially expressed in Tregs, especially in effector Tregs, and is essential for Treg expansion and function maintenance through the classical NF- $\mathrm{KB}$ pathway. Meanwhile, some new molecules have also been found involved in the TNFR2 pathway.

Targeting Tregs through TNFR2 antagonists seems really promising in antitumor therapy. Interestingly, there is evidence that some TNFR2 agonists also show antitumor effects in vivo; some of those agonists are now in the investigational new drug (IND)-enabling phase and about to undergo clinical trials. It seems that all roads lead to Rome when targeting TNFR2 in the tumor. Here, we will review the most potential TNFR2 antagonists and agonists that are about to get into or 
already under clinical trials and try to explain why both blocking and activating TNFR2 can inhibit tumor cells in vivo. The answers might lie in the complex reactions of those nonmalignant cells in the TME.

\section{TNF $\alpha$, TNFR, AND THEIR SIGNAL PATHWAY}

TNF $\alpha$ was first found in mice treated with bacterial endotoxin, a serological protein with necrotic antitumor activity, and hence was named tumor necrosis factor $\alpha(\mathrm{TNF} \alpha)$ (5). There are two forms of TNF $\alpha$ : soluble and transmembrane TNF $\alpha$ (sTNF $\alpha$ and tmTNF $\alpha$ ). Transmembrane TNF $\alpha$ can be processed by TNF $\alpha$ converting enzyme (TACE) to release the soluble one, and both of them are biologically active $(6,7)$. Many cell types are able to produce sTNF $\alpha$, and the myeloid cells and activated T cells are the highest producers of this cytokine in the immune cells (8). tmTNF $\alpha$ is expressed on a bunch of immune cells such as macrophages and monocytes (9), dendritic cells (DCs), and natural killer (NK) cells (10). Studies have verified that tumor cells, such as in breast cancer, ovarian cancer, liver cancer, lung cancer, gastric cancer, acute lymphoblastic leukemia, and lymphoma, strongly express tmTNF $\alpha$ (11).

There are two receptors of TNF $\alpha$ : TNF receptor 1 (TNFR1) and TNFR2 (12). TNF $\alpha$ can bind to both TNFR1 and TNFR2; however, it is shown that sTNF $\alpha$ has a higher affinity for TNFR1, while tmTNF $\alpha$ favors TNFR2 a lot $(13,14)$. When binding to TNFR2, tmTNF $\alpha$ can mediate both forward and reverse signaling between tmTNF- $\alpha$ - and TNFR2-expressing cells (15, 16). These receptors can be enzymatically cleaved from the cell surface and form soluble TNF $\alpha$ receptors: sTNFR1 and sTNFR2. sTNFRs may inhibit TNF $\alpha$ bioactivity by binding to sTNF $\alpha$ and tmTNF $\alpha$, or stabilize the trimeric structure of TNF $\alpha$ and prolong its bioactivity, or stimulate $\operatorname{tm} \mathrm{TNF} \alpha$, leading to a reverse activation signal in macrophage cells, which express more tmTNF $\alpha$ than others $(15,17)$.

Upon TNF $\alpha$ binding to TNFR1, the cytoplasmic tail of TNFR1 recruits the adaptor protein TNFR1-associated death domain (TRADD) via its death domain. TRADD then interacts with TRAF2, RIPK1, or cIAP1and cIAP2 to form complex 1; and complex 1 ultimately leads to the activation of NF- $\kappa B$ and MAPK pathways by phosphorylating and ubiquitylating other molecules. This complex 1 pathway favors cell proliferation and survival. However, when TRADD recruits Fas-associated death domain (FADD) adaptors RIPK1 and RIPK3, complex 2 forms and leads to cell death $(18,19)$. In contrast to TNFR1, TNFR2 does not contain a death domain module. When TNFR2 is activated by TNF $\alpha$, the intracellular domain of TNFR2 will recruit TRAF2/ cIAP1/cIAP2 complexes $(20,21)$, resulting in the initiation of both canonical and non-canonical NF- $\mathrm{KB}$ activation (22-25). The PI3K/ Akt pathway can also be activated reciprocally (26). Interestingly, TNFR2-dependent P38 activation varies in different cells. p38 MAPK will be activated in macrophages and murine B cells upon TNFR2 stimulation $(27,28)$. TNF $\alpha$-induced upregulation of TNFR2 can be abrogated by p38 MAPK-specific inhibitor in CD4+ T cells (29). However, TNFR2 stimulation on TNFR2- overexpressing cancer cell lines does not result in p38 MAPK activation (30). Moreover, TNFR2 can also induce cell death indirectly by crosstalk with TNFR1 (22).

Recently, some new molecules have been found to be involved in the TNFR2 pathway. 14-3-3€ was recently identified as a new intracellular component of TNFR2 complexes in chondrocytes when triggered with progranulin (PGRN), and TNFR2/14-3-3€ signals through activating EIK-1 and suppressing NF- $\kappa \mathrm{B}$ in chondrocytes (31). However, 14-3-3€ may play a totally different role in immunosuppressive cells in TMEs, and this needs to be proved in the future. It was verified that cardiac myocytes benefit from protection from TNFR2 activation against stress by upregulation of optic atrophy 1 (OPA1) expression, which results in improvements in mitochondrial morphology and function. This process was facilitated by p300-mediated Stat 3 acetylation and Stat3/RelA interactions (32). There might be other molecules involved in the TNFR2 pathway that need to be found in the future.

\section{TNFR2 IS HIGHLY EXPRESSED IN Tregs AND ESSENTIAL FOR FUNCTION MAINTENANCE}

Tregs are the most extensively studied immunosuppressive cells, and they are defined as CD4+CD25+Foxp3+ or CD4+CD25+ CD127low $\mathrm{T}$ cells $(33,34)$. Current research suggests that TNFR2 is highly expressed in Tregs, especially in effector Tregs, while TNFR1 is hardly detected (35-37). The presence of high Tregs, especially TNFR2+ Tregs in the TME, is associated with an unfavorable prognosis in various types of cancers (3840). Tregs in the peripheral blood of lung cancer patients express high levels of TNFR2, which is associated with advanced clinical stage and poor prognosis (41). This is the same situation in patients with septic shock where TNFR2+ circulating Tregs are more immunosuppressive (42).

TNF $\alpha$ can preferentially expand CD4+Foxp3+ Tregs in vitro through TNFR2 (43). Other TNFR family members, such as 41BB, GITR, and DR3, but not OX40, can also increase Tregs' proliferation and survival through canonical NF- $\kappa B$; TNFR2 is the most efficient among them, and the transcriptome feature of each group seems to be similar (44). Tsunoda et al. reported the generation of a new TNFR2-selective agonist TNF $\alpha$ mutant, termed R2gaoTNF; it could expand and activate mouse CD4+ CD25+ Tregs ex vivo, which makes it a new candidate for Treg expansion (45). Another novel TNFR2 agonist antibody developed by Faustman can also expand highly potent Tregs $(25,46)$. Another novel dimeric dual-acting fusion cytokine combining IL-2 and TNFR2-selective single-chain TNF mutein (IL2-EHD2-sc-mTNFR2) showed high affinity and activation of TNFR2 and IL-2R and thus promoted superior Treg expansion (47). Paeoniflorin can ameliorate lupus nephritis in lupus-prone B6/gld mice by increasing TNFR2 expression on CD4+FoxP3+ Tregs (48).

However, some researchers think that the role of TNF $\alpha$ on the Tregs seems to be more complicated than it appears. On the 
one hand, TNF $\alpha$ may promote the degradation of Foxp3 by activating caspase- 8 in Tregs (49) or may inhibit the expression of Foxp3 (50). On the other hand, TNF $\alpha$ is important for both the development and maintenance of the function of Tregs (51). This still needs to be further investigated.

There is evidence that not only tumor-infiltrating Tregs but also tumor-draining lymph nodes (TDLNs) TNFR2+ Tregs are involved in tumor progression and metastasis. Some researchers compared Tregs from tumors and matched tumor-invaded and non-invaded TDLNs, and Tregs showed conserved suppressive function in TDLN and tumor. Moreover, a common transcriptomic signature sharing by Tregs from tumors and lymph nodes was also described. TNFRSF1B transcription was alleviated obviously in Tregs in both tumor and TDLNs, regardless of lymph nodes with tumor invasion or not (52). There is also other evidence indicating that the majority of CD4 +CD25+Foxp3+ Tregs are TNFR2+, and they expressed TNFR2 with the highest intensity in the TDLNs of breast cancer, up to $90.5 \% \pm 11.3 \%$, when compared with other CD4+ T cells, which highlights the importance of TNFR2 in Tregs (53). However, they also found that most TNFR2+CD4+ T cells were Foxp3 -CD25- in the TDLNs. It seems that TNFR2 is more vital in Tregs, but we cannot ignore the majority expression of TNFR2 in Foxp3-CD4+ T cells when considering targeting TNFR2 treatment, which may influence the therapy effects or shed light on combination therapies.

\section{TARGETING TNFR2: BLOCKING AND ACTIVATING DRUGS UNDER CLINICAL TRIALS OR PRECLINICAL DEVELOPMENTS}

TNF $\alpha$ inhibitors have now been widely used in patients with autoimmune diseases and have greatly improved their outcomes. Considering TNFR2's high expression and its important role in Tregs, it makes targeting TNFR2 a promising immunotherapeutic approach (Table 1). However, all these data are from abstracts of AACR Annual Meeting or company media releases, most of these antibodies are still in the early stages of development, and detailed information is unpublished. Aside from the important role that TNFR2 plays in Tregs, TNFR2 is also an oncogene upregulated in certain tumors and can improve cancer cell survival. Therefore, TNFR2 antagonists can block both immunosuppressive cells and certain tumor cells, which have the effect of killing two birds with one stone.

There are several TNFR2 antagonist antibodies that seem to be promising in the clinical transformation, some of them have already undergone clinical study, and others are about to undergo clinical trials. BI-1808 is a fully human IgG1 mAb that targets TNFR2. A phase $1 / 2$ a study of BI-1808 as a single agent or in combination with pembrolizumab in subjects with advanced malignancies is now recruiting. Dose escalation and safety will be assessed in a phase 1 study. Evaluation of BI-1808 infusions as a single dose in ovarian cancer, non-small cell lung cancer, and cutaneous T-cell lymphoma (Sézary syndrome and mycosis fungoides) or in combination with pembrolizumab in ovarian cancer and non-small cell lung cancer will be carried out in a phase 2a study. iRECIST is applied for efficacy assessment of targeting TNFR2 alone or in combination therapy (54). The mechanism of BI-1808 was mediated through intra-tumor Treg depletion, CD8+ T-cell expansion, and modulation of tumorassociated myeloid cells. These findings were confirmed in a humanized mouse model (55). BITR2101 from Boston Immune Technologies and Therapeutics is about to conduct phase 1 clinical trials in order to test the effectiveness of the agent alone or in combination with anti-PD-1 antibody tislelizumab (56). APX601 is a rabbit monoclonal antagonist antibody from Apexigen Inc., which has a high binding affinity of TNFR2. It can reverse immune suppression by targeting TNFR2-expressing Tregs and myeloid-derived suppressor cells (MDSCs) and induce the killing of tumor cells $(57,58)$. AN3025 from Adlai Nortye can significantly inhibit MC38 tumor growth without impaction on body weight through Treg depletion and increased expression of IFN $\gamma$ and granzyme. In addition, the combined use of AN3025 and PD-1 antibody can achieve a synergistic effect in vivo (59). SIM0235 is a mAb that targets and inhibits TNFR2 from Simcere. It is able to kill TNFR2+ Tregs and MDSCs through antibody-dependent cellular cytotoxicity (ADCC), antibody-dependent cellular phagocytosis (ADCP), and other Fc-receptor functions. Meanwhile, it is able to kill TNFR2+ tumor cells directly. SIM0235 also has significant antitumor efficacy and synergistic effects when combined with PD-L1 antibodies (60). LBL-019 from Leads Biolabs is a TNFR2 antagonist aiming at malignant tumors. It is a first-in-class drug targeting TNFR2 that has been approved for a clinical trial in China and has also been recently approved for a clinical trial by the Food and Drug Administration (FDA) according to its official website. Unfortunately, we could not find more detailed information about that (61). NBL-020 from NovaRock Biotherapeutics can block TNF $\alpha$ ligand binding and potently inhibit TNFR2 signaling in the monocytic cells. Moreover, it can enhance CD8 T-cell function to overcome the suppressive effect from Tregs and invigorate exhausted CD8 T cells in an Fc $\gamma \mathrm{R}$ dependent manner. The antitumor effects alone or in combination with PD-L1 inhibitors were also confirmed in vivo. This NBL-020 is currently at the IND-enabling stage (62).

It is easy to understand the mechanisms of targeting tumors with TNFR2 antagonists, and blocking TNFR2 may have the effect of killing two birds with one stone: boosting antitumor immune responses and directly killing TNFR2 overexpressing tumor cells and tumor mesenchymal cells. However, there are TNFR2 agonist antibodies that also have remarkable antitumor effects in vivo.

In addition to BI-1808, BI-1910 from BioInvent International $\mathrm{AB}$ is a TNFR2 agonist antibody that is administered in preclinical development. Its potent antitumor efficacy has been demonstrated both as a single agent and in combination with anti-PD-1 through dramatic CD8+ T-cell increases, which results in improved CD8/ Treg ratios and tumor regression (63). HFB200301 is a first-inclass agonistic anti-TNFR2 agonist antibody that binds potently and selectively to TNFR2, which demonstrates potent antitumor 
TABLE 1 | TNFR2 antibodies under clinical trials or preclinical developments.

\begin{tabular}{|c|c|c|c|c|c|c|}
\hline & Name & Producer & Stage of development & Condition or disease & Reported mechanisms & References \\
\hline \multirow[t]{7}{*}{ Antagonist } & $\mathrm{Bl}-1808$ & $\begin{array}{l}\text { Biolnvent } \\
\text { International } \mathrm{AB}\end{array}$ & $\begin{array}{l}\text { Phase 1/2a (NCT04752826): } \\
\text { monotherapy or combination } \\
\text { with anti-PD-1 (Merck) }\end{array}$ & $\begin{array}{l}\text { Human advanced } \\
\text { malignancies }\end{array}$ & $\begin{array}{l}\text { a) Intra-tumor Treg depletion } \\
\text { b) CD8+ T-cell expansion } \\
\text { c) Modulation of tumor-associated myeloid } \\
\text { cells }\end{array}$ & $(54,55)$ \\
\hline & BITR2101 & $\begin{array}{l}\text { Boston Immune } \\
\text { Technologies \& } \\
\text { Therapeutics Inc. }\end{array}$ & $\begin{array}{l}\text { Preclinical development (IND } \\
\text { enabling) }\end{array}$ & Caner (not detailed) & Not detailed & $(56)$ \\
\hline & APX601 & Apexigen Inc. & $\begin{array}{l}\text { Preclinical development (IND } \\
\text { enabling) }\end{array}$ & $\begin{array}{l}\text { Mouse cancer model } \\
\text { (CT26 and MC38) }\end{array}$ & $\begin{array}{l}\text { a) Blockade of the immunosuppressive } \\
\text { functions of both Tregs and MDSCs } \\
\text { b) Depletion of TNFR2-expressing Tregs, } \\
\text { MDSC, and tumor cells via ADCC and } \\
\text { ADCP } \\
\text { c) Tumor growth inhibition both as a single } \\
\text { agent and in combination with anti-PD-1 }\end{array}$ & $(57,58)$ \\
\hline & AN3025 & Adlai Nortye & Preclinical development & $\begin{array}{l}\text { Jurkat cell line } \\
\text { Mouse cancer model } \\
\text { (MC38) }\end{array}$ & $\begin{array}{l}\text { a) Treg depletion } \\
\text { b) Increased IFN } \gamma \text { and granzyme } \\
\text { expression } \\
\text { c) Synergistic effect with anti-PD-1 }\end{array}$ & (59) \\
\hline & SIM0235 & Simcere & $\begin{array}{l}\text { Preclinical development (IND } \\
\text { enabling) }\end{array}$ & Cancer (not detailed) & $\begin{array}{l}\text { a) Kill TNFR2+ Tregs and MDSCs through } \\
\text { ADCC and ADCP } \\
\text { b) Kill TNFR2+ tumor cells } \\
\text { c) Synergistic effects with anti-PD-L1 }\end{array}$ & $(60)$ \\
\hline & LBL-019 & $\begin{array}{l}\text { Nanjing Leads } \\
\text { Biolabs Co. Ltd. }\end{array}$ & $\begin{array}{l}\text { Phase } 1 \text { (in both China and the } \\
\text { USA) }\end{array}$ & Cancer (not detailed) & Not detailed & (61) \\
\hline & NBL-020 & $\begin{array}{l}\text { NovaRock } \\
\text { Biotherapeutics }\end{array}$ & $\begin{array}{l}\text { Preclinical development (IND } \\
\text { enabling) }\end{array}$ & Mouse cancer model & $\begin{array}{l}\text { a) Enhance CD8 T-cell function through } \\
\text { overcoming the suppressive effect from } \\
\text { Tregs } \\
\text { b) Invigorate exhausted CD8 T cells in an } \\
\text { FcyR-dependent manner } \\
\text { c) Synergistic effects with anti-PD-L1 }\end{array}$ & (62) \\
\hline \multicolumn{7}{|l|}{ Agonist } \\
\hline & $\mathrm{Bl}-1910$ & $\begin{array}{l}\text { Biolnvent } \\
\text { International } A B\end{array}$ & Preclinical development & $\begin{array}{l}\text { Mouse cancer model } \\
\text { (CT26, MC38 and B16), }\end{array}$ & $\begin{array}{l}\text { a) Increase CD8+ T cell } \\
\text { b) Improved CD8/Treg ratios } \\
\text { c) synergistic effects with anti-PD-1 }\end{array}$ & (63) \\
\hline & HFB200301 & $\begin{array}{l}\text { HiFiBiO } \\
\text { Therapeutics }\end{array}$ & $\begin{array}{l}\text { Preclinical development (IND } \\
\text { enabling) }\end{array}$ & $\begin{array}{l}\text { Mouse cancer model } \\
\text { (MC38) }\end{array}$ & $\begin{array}{l}\text { a) Activates CD4+, CD8+ T cells, and } \\
\text { NK cells in vitro } \\
\text { b) Expand CD4+T/CD8+T/NK cells in } \\
\text { TME without affecting Tregs numbers in } \\
\text { vivo }\end{array}$ & (64) \\
\hline & MM-401 & $\begin{array}{l}\text { Merrimack } \\
\text { Pharmaceuticals, } \\
\text { Inc. }\end{array}$ & Preclinical development & $\begin{array}{l}\text { T cells from healthy } \\
\text { donors; ovarian cancer } \\
\text { ascites samples }\end{array}$ & $\begin{array}{l}\text { a) Upregulation of activation markers and } \\
\text { cytokine production of CD4+ and CD8+ T } \\
\text { cells from Healthy donors } \\
\text { b) Promote ADCC and deplete Tregs in } \\
\text { ovarian cancer ascites samples }\end{array}$ & $(65,66)$ \\
\hline
\end{tabular}

IND, investigational new drug; MDSCs, myeloid-derived suppressor cells; ADCC, antibody-dependent cellular cytotoxicity; ADCP, antibody-dependent cellular phagocytosis.

activity alone and in combination with anti-PD-1. HFB200301 activates CD4+, CD8+ T cells, and NK cells in vitro and induces expansion of CD4+ and CD8+ T cells and NK cells in the TME without affecting regulatory $\mathrm{T}$ cells numbers in vivo (64). Another TNFR2 agonist antibody is MM-401, which shows T-cell costimulation and robust antitumor activity and immune memory in a mouse. It can also upregulate activation markers and cytokine production of $\mathrm{CD} 4+$ and $\mathrm{CD} 8+\mathrm{T}$ cells from healthy donors, as well as promote ADCC in an NK cell-mediated in vitro assay and deplete Tregs in ovarian cancer ascites samples; all these results are going to be retested in patient-derived xenograft (PDX) mouse models $(65,66)$.

It seems that all roads lead to Rome in either blocking or activating TNFR2 in the tumor. How these two contradictory drugs achieve the same antitumor effect remains to be investigated. TME is an indivisible whole complexity, all the members in this environment may influence each other, and they may react differently in different TNFR2 treatments. Here, we show some typical cell types other than Tregs in TME, which may be involved in targeting TNFR2 (Figure 1).

\section{NON-MALIGNANT CELLS INVOLVED IN TARGETING TNFR2 IN TME \\ CD8+ T Cells}

Previous studies found that TNFR2, but not TNFR1, were the predominant TNF receptor on CD8+ effector T cells $(67,68)$; the proportion of proliferating transgenic tumor-specific CD8+ 


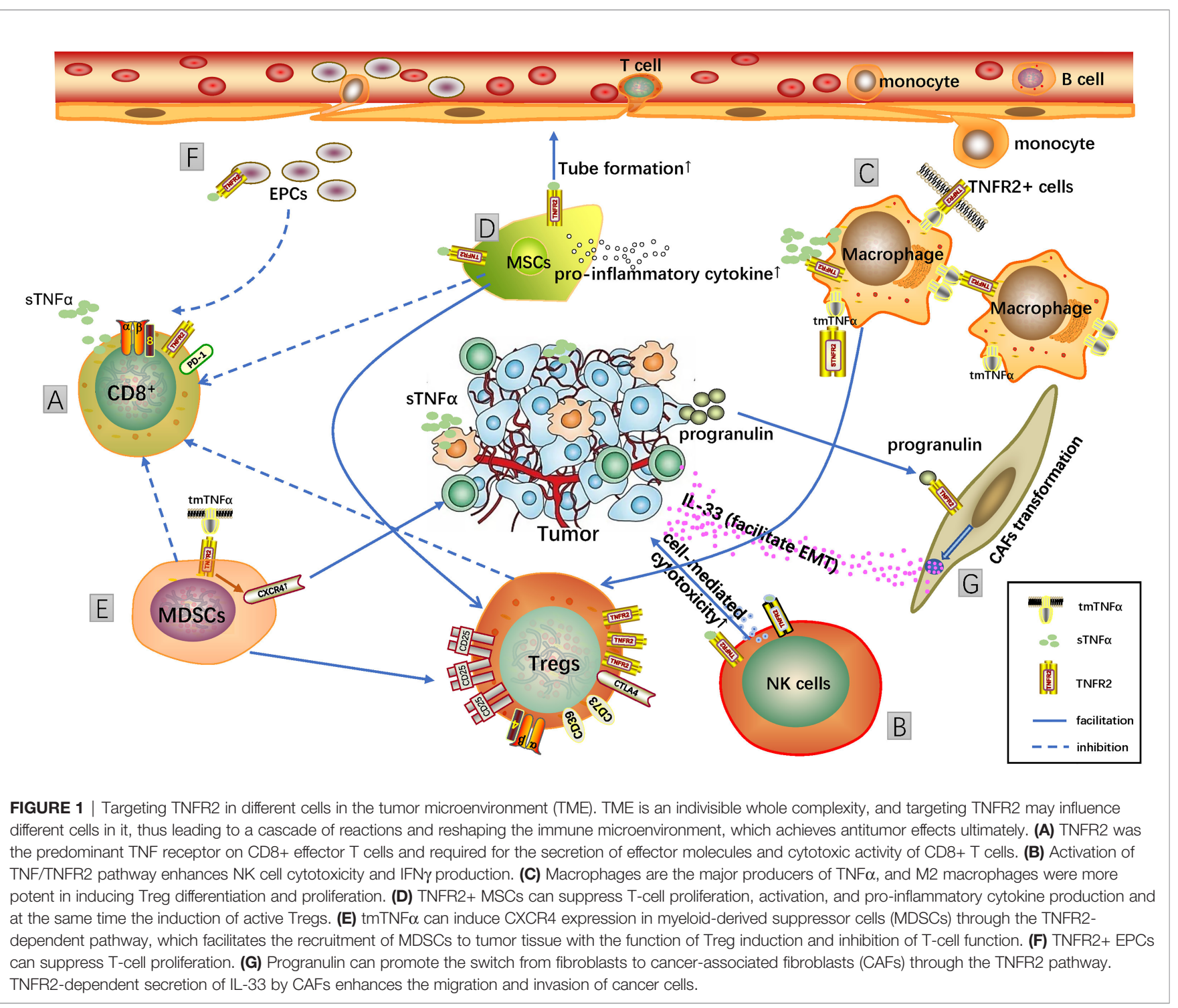

$\mathrm{T}$ cells in TNFR2 deficient mice was significantly reduced in TDLNs (67). TNFR2 is also required for the secretion of effector molecules and cytotoxic activity of CD8+ T cells (69). Some CD8 + T cells can also secrete cytokines, which include TNF $\alpha$ (70), and TNF $\alpha$ could influence other TNFR+ cells.

A mouse TNFR2 agonist antibody Y9 was identified and had antitumor effects in mouse models, and the effects were mediated by CD8+ T cells and NK cells. TNFR2 agonist treatment could downregulate TNFR2 on $\mathrm{T}$ cells, thus leading to CD8+ T-cell expansion and function improvement. However, this agonist did not deplete Tregs. Meanwhile, they generated a parallel anti-human TNFR2 antibody Ab1, which exhibits similar properties to the Y9 antibody, and it can increase proliferation, activation markers, and cytokines in both CD4+ and CD8+ T cells. Moreover, it also has antitumor activity in humanized mouse models (71). This result broke the initial thinking that targeting TNFR2 in cancer only means blocking, and it shed light on the potential possibility of TNFR2 agonist antibodies as antitumor agents in preclinical development.

\section{Natural Killer Cells}

TNFR2 plays a vital role in the function maintenance of NK cells. NK cells play a central role in the antitumor process in TME (2), acting directly through cell-mediated cytotoxicity and by secreting cytokines. Activation of the TNF/TNFR2 pathway enhances NK cell cytotoxicity, and TNF $\alpha$ also enhanced murine NK cell IFN $\gamma$ production via TNFR2 in vivo and in vitro (72). DC TNF $\alpha$ and NK cell TNFR2 are required for DC-mediated NK cell proliferation and amplification of cytotoxic activity (10).

\section{Macrophages}

Macrophages are the major producers of TNF $\alpha$ and interestingly are also highly responsive to TNF $\alpha$ through TNFR1 and TNFR2 (73). TNFR2-positive tumor-associated macrophages were related to the metastasis of human triple-negative breast cancer (74). tmTNF $\alpha$ can act as a receptor when interacting with sTNFR2- or TNFR2-expressing cells. This reverse signaling is proven to be profoundly important in the activation of 
monocytes $(15,75)$. The reverse signaling activated by mTNF $\alpha$ could increase the production of TNF $\alpha$ (75). tmTNF $\alpha+\mathrm{M} 2$ macrophages were more potent in inducing Treg differentiation and proliferation (48). 14-3-3€ was essential for TNFR2 signaling-mediated regulation of macrophage polarization and switch (76).

\section{Mesenchymal Stem Cells}

Mesenchymal stem cells (MSCs) have the ability to modulate the immune response and belong to immunosuppressive cells. TNFR2 is a key regulator strongly involved in the immunosuppressive properties of MSCs. This includes suppression of T-cell proliferation, activation, and pro-inflammatory cytokine production and at the same time the induction of active Tregs (77). TNFR2 expression by MSCs is also associated with enhanced tube formation property. TNFR2 plays a critical role in controlling MSC biological and functional properties $(78,79)$.

\section{Myeloid-Derived Suppressor Cells}

MDSCs are well known for their capacity of promoting immune evasion in tumor sites. $\operatorname{tmTNF} \alpha$ can induce CXCR4 expression in MDSCs through the TNFR2-dependent pathway, which facilitates the recruitment of MDSCs to tumor tissue. CXCR4 inhibitor could impair the MDSC accumulation in tumors of $\mathrm{TNFR}^{-/-}$mice after the restoration of adoptive transfer of wildtype MDSCs (80). So tmTNF $\alpha$ acts as a potent activator of MDSCs via the TNFR2 pathway and promotes tumor immune escape (81). Moreover, the ability of MDSCs to induce Tregs in vivo has been described $(82,83)$, and they can also inhibit T-cell function in a non-specific manner (84).

\section{Endothelial Cells and EPCs}

Endothelial progenitor cells (EPCs) are non-differentiated endothelial cells (ECs). They are involved in cancer-associated neo-vascularization, thus facilitating cancer progression (85). Evidence showed that EPCs were able to suppress T-cell proliferation, and the TNF $\alpha / T N F R 2$ signaling pathway in EPCs played a key regulatory factor in this immunosuppressive effect (86). Adequate TNF $\alpha$ preconditioning could increase TNFR2 expression without an unrestrained increase of TNFR1 and prime EPCs towards more immunosuppressive functions (87).

\section{Cancer-Associated Fibroblasts}

Cancer-associated fibroblasts (CAFs) are the activated fibroblasts in cancer stroma that can promote cancer progression by the secretion of cytokines and interaction with the local extracellular matrix. In gastric cancer, CAF-derived IL-33 enhances the migration and invasion of gastric cancer cells by inducing the epithelial-mesenchymal transition (EMT), and the secretion of

\section{REFERENCES}

1. Hsu A, Mendelson L, Almhanna K. Immune Checkpoint Inhibitors in the Treatment of Gastrointestinal Malignancies: A Review of Current and Future Therapies. R I Med J (2020) 103(3):33-7.
IL-33 by CAFs is dependent on the activation of the TNFR2-NFКB-IRF1 pathway (88). Progranulin secreted by colorectal cancer cells can promote the switch from fibroblasts to CAFs through the TNFR2 pathway (89).

\section{TNFR2 IN TUMOR CELLS}

Besides immune and mesenchymal cells, increased TNFR2 expression has also been found in several types of tumors, such as ovarian cancer, colon cancer, kidney cancer, and T-cell lymphomas $(39,90-93)$. It seems that hematopoietic and lymphoid cells have the highest expression of TNFR2 in 788 human tumor cell lines (93), which indicated their vital role in the maintenance of tumor cell vitality. In the retrospective studies, TNFR2 expression is higher in tumor sites than non-tumor sites in esophageal cancer, and TNFR2 is positively correlated with high malignancy and poorer survival (94). Similar results have been obtained in non-small cell lung cancer and ovarian cancer $(95,96)$.

\section{DISCUSSION}

TNFR2 has emerged as a potential immune checkpoint in cancer treatment; however, the role it played in TME is much more complex than we thought. The antitumor effects of targeting TNFR2 can be concluded as direct inhibition of cell proliferation and influence immune cells and then kill tumor cells indirectly. TNFR2 antagonist antibodies can inhibit TNFR2-positive cancer cells and tumor supporting cells, such as CAFs, ECs, and EPCs, directly by signal interference. TNFR2 antibodies could also attenuate the function of immunosuppressive cells or enhance the killing ability of effector T cells directly to achieve antitumor effects. A new mechanism needs to be deployed considering the complicated network of TME. Meanwhile, we are looking forward to the results of these clinical trials and hoping targeting TNFR2 may achieve huge success in immunotherapy and benefit more tumor patients.

\section{AUTHOR CONTRIBUTIONS}

JB was responsible for the data collection and the draft of the manuscript. BD gave the necessary assistance to finish the manuscript. HL designed the project and modified the paper.

\section{FUNDING}

This study was funded by the National Natural Science Foundation of China (grant number 82171728).

2. Yang Y, Islam MS, Hu Y, Chen X. TNFR2: Role in Cancer Immunology and Immunotherapy. Immunotargets Ther (2021) 10:103-22. doi: 10.2147/ITT.S255224

3. Jin MZ, Jin WL. The Updated Landscape of Tumor Microenvironment and Drug Repurposing. Signal Transduct Target Ther (2020) 5(1):166. doi: 10.1038/s41392-020-00280-x 
4. Kang W, Feng Z, Luo J, He Z, Liu J, Wu J, et al. Tertiary Lymphoid Structures in Cancer: The Double-Edged Sword Role in Antitumor Immunity and Potential Therapeutic Induction Strategies. Front Immunol (2021) 12:689270. doi: 10.3389/ fimmu.2021.689270

5. Carswell EA, Old LJ, Kassel RL, Green S, Fiore N, Williamson B. An Endotoxin-Induced Serum Factor That Causes Necrosis of Tumors. Proc Natl Acad Sci USA (1975) 72(9):3666-70. doi: 10.1073/pnas.72.9.3666

6. Kruglov A, Drutskaya M, Schlienz D, Gorshkova E, Kurz K, Morawietz L, et al. Contrasting Contributions of TNF From Distinct Cellular Sources in Arthritis. Ann Rheum Dis (2020) 79(11):1453-9. doi: 10.1136/annrheumdis2019-216068

7. Nguyen DX, Ehrenstein MR. Anti-TNF Drives Regulatory T Cell Expansion by Paradoxically Promoting Membrane TNF-TNF-RII Binding in Rheumatoid Arthritis. J Exp Med (2016) 213(7):1241-53. doi: 10.1084/jem.20151255

8. Kruglov AA, Lampropoulou V, Fillatreau S, Nedospasov SA. Pathogenic and Protective Functions of TNF in Neuroinflammation are Defined by its Expression in T Lymphocytes and Myeloid Cells. J Immunol (2011) 187 (11):5660-70. doi: 10.4049/jimmunol.1100663

9. Armstrong L, Thickett DR, Christie SJ, Kendall H, Millar AB. Increased Expression of Functionally Active Membrane-Associated Tumor Necrosis Factor in Acute Respiratory Distress Syndrome. Am J Respir Cell Mol Biol (2000) 22(1):68-74. doi: 10.1165/ajrcmb.22.1.3728

10. Xu J, Chakrabarti AK, Tan JL, Ge L, Gambotto A, Vujanovic NL. Essential Role of the TNF-TNFR2 Cognate Interaction in Mouse Dendritic CellNatural Killer Cell Crosstalk. Blood (2007) 109(8):3333-41. doi: 10.1182/ blood-2006-06-026385

11. Li X, Wang S, Ren H, Ma J, Sun X, Li N, et al. Molecular Correlates and Prognostic Value of Tmtnf-Alpha Expression in Colorectal Cancer of 5Fluorouracil-Based Adjuvant Therapy. Cancer Biol Ther (2016) 17(6):684-92. doi: 10.1080/15384047.2016.1187551

12. Richter F, Williams SK, John K, Huber C, Vaslin C, Zanker H, et al. The TNFR1 Antagonist Atrosimab is Therapeutic in Mouse Models of Acute and Chronic Inflammation. Front Immunol (2021) 12:705485. doi: 10.3389/ fimmu.2021.705485

13. Grell M, Wajant H, Zimmermann G, Scheurich P. The Type 1 Receptor (CD120a) is the High-Affinity Receptor for Soluble Tumor Necrosis Factor. Proc Natl Acad Sci U.S.A. (1998) 95(2):570-5. doi: 10.1073/pnas.95.2.570

14. Grell M, Douni E, Wajant H, Lohden M, Clauss M, Maxeiner B, et al. The Transmembrane Form of Tumor Necrosis Factor is the Prime Activating Ligand of the 80 Kda Tumor Necrosis Factor Receptor. Cell (1995) 83(5):793802. doi: $10.1016 / 0092-8674(95) 90192-2$

15. Qu Y, Zhao G, Li H. Forward and Reverse Signaling Mediated by Transmembrane Tumor Necrosis Factor-Alpha and TNF Receptor 2: Potential Roles in an Immunosuppressive Tumor Microenvironment. Front Immunol (2017) 8:1675. doi: 10.3389/fimmu.2017.01675

16. Lee WH, Seo D, Lim SG, Suk K. Reverse Signaling of Tumor Necrosis Factor Superfamily Proteins in Macrophages and Microglia: Superfamily Portrait in the Neuroimmune Interface. Front Immunol (2019) 10:262. doi: 10.3389/ fimmu.2019.00262

17. Kieszko R, Krawczyk P, Chocholska S, Bojarska-Junak A, Jankowska O, Krol A, et al. Tumor Necrosis Factor Receptors (Tnfrs) on T Lymphocytes and Soluble Tnfrs in Different Clinical Courses of Sarcoidosis. Respir Med (2007) 101(3):645-54. doi: 10.1016/j.rmed.2006.06.004

18. Medler J, Wajant H. Tumor Necrosis Factor Receptor-2 (TNFR2): An Overview of an Emerging Drug Target. Expert Opin Ther Targets (2019) 23 (4):295-307. doi: 10.1080/14728222.2019.1586886

19. Atretkhany KN, Gogoleva VS, Drutskaya MS, Nedospasov SA. Distinct Modes of TNF Signaling Through its Two Receptors in Health and Disease. J Leukoc Biol (2020) 107(6):893-905. doi: 10.1002/JLB.2MR0120-510R

20. Rothe M, Wong SC, Henzel WJ, Goeddel DV. A Novel Family of Putative Signal Transducers Associated With the Cytoplasmic Domain of the $75 \mathrm{Kda}$ Tumor Necrosis Factor Receptor. Cell (1994) 78(4):681-92. doi: 10.1016/ 0092-8674(94)90532-0

21. Vanamee ES, Faustman DL. Structural Principles of Tumor Necrosis Factor Superfamily Signaling. Sci Signal (2018) 11(511):eaao4910. doi: 10.1126/ scisignal.aao4910

22. Naude PJ, den Boer JA, Luiten PG, Eisel UL. Tumor Necrosis Factor Receptor Cross-Talk. FEBS J (2011) 278(6):888-98. doi: 10.1111/j.1742-4658.2011.08017.x
23. Sun SC, Ley SC. New Insights Into NF-Kappab Regulation and Function. Trends Immunol (2008) 29(10):469-78. doi: 10.1016/j.it.2008.07.003

24. Rauert H, Wicovsky A, Muller N, Siegmund D, Spindler V, Waschke J, et al. Membrane Tumor Necrosis Factor (TNF) Induces P100 Processing via TNF Receptor-2 (TNFR2). J Biol Chem (2010) 285(10):7394-404. doi: 10.1074/ jbc.M109.037341

25. Torrey H, Kuhtreiber WM, Okubo Y, Tran L, Case K, Zheng H, et al. A Novel TNFR2 Agonist Antibody Expands Highly Potent Regulatory T Cells. Sci Signal (2020) 13(661):eaba9600. doi: 10.1126/scisignal.aba9600

26. Marchetti L, Klein M, Schlett K, Pfizenmaier K, Eisel UL. Tumor Necrosis Factor (TNF)-Mediated Neuroprotection Against Glutamate-Induced Excitotoxicity is Enhanced by N-Methyl-D-Aspartate Receptor Activation. Essential Role of a TNF Receptor 2-Mediated Phosphatidylinositol 3-KinaseDependent NF-Kappa B Pathway. J Biol Chem (2004) 279(31):32869-81. doi: 10.1074/jbc.M311766200

27. Mukhopadhyay A, Suttles J, Stout RD, Aggarwal BB. Genetic Deletion of the Tumor Necrosis Factor Receptor P60 or P80 Abrogates Ligand-Mediated Activation of Nuclear Factor-Kappa B and of Mitogen-Activated Protein Kinases in Macrophages. J Biol Chem (2001) 276(34):31906-12. doi: 10.1074/ jbc.M105252200

28. Zhao Y, Conze DB, Hanover JA, Ashwell JD. Tumor Necrosis Factor Receptor 2 Signaling Induces Selective C-IAP1-Dependent ASK1 Ubiquitination and Terminates Mitogen-Activated Protein Kinase Signaling. J Biol Chem (2007) 282(11):7777-82. doi: 10.1074/jbc.M609146200

29. He T, Liu S, Chen S, Ye J, Wu X, Bian Z, et al. The P38 MAPK Inhibitor SB203580 Abrogates Tumor Necrosis Factor-Induced Proliferative Expansion of Mouse CD4(+)Foxp3(+) Regulatory T Cells. Front Immunol (2018) 9:1556. doi: 10.3389/fimmu.2018.01556

30. Jupp OJ, McFarlane SM, Anderson HM, Littlejohn AF, Mohamed AA, MacKay RH, et al. Type II Tumour Necrosis Factor-Alpha Receptor (TNFR2) Activates C-Jun N-Terminal Kinase (JNK) But Not MitogenActivated Protein Kinase (MAPK) or P38 MAPK Pathways. Biochem J (2001) 359(Pt 3):525-35. doi: 10.1042/bj3590525

31. Fu W, Hettinghouse A, Chen Y, Hu W, Ding X, Chen M, et al. 14-3-3 Epsilon is an Intracellular Component of TNFR2 Receptor Complex and its Activation Protects Against Osteoarthritis. Ann Rheum Dis (2021) 80(12):1615-27. doi: 10.1136/annrheumdis-2021-220000

32. Nan J, Hu H, Sun $Y$, Zhu L, Wang $Y$, Zhong Z, et al. TNFR2 Stimulation Promotes Mitochondrial Fusion via Stat3-and NF-Kb-Dependent Activation of OPAl Expression. Circ Res (2017) 121(4):392-410. doi: 10.1161/ CIRCRESAHA.117.311143

33. Ohue Y, Nishikawa H. Regulatory T (Treg) Cells in Cancer: Can Treg Cells be a New Therapeutic Target? Cancer Sci (2019) 110(7):2080-9. doi: 10.1111/ cas. 14069

34. Liu W, Putnam AL, Xu-Yu Z, Szot GL, Lee MR, Zhu S, et al. CD127 Expression Inversely Correlates With Foxp3 and Suppressive Function of Human CD4+ T Reg Cells. J Exp Med (2006) 203(7):1701-11. doi: 10.1084/ jem.20060772

35. Urbano PCM, He X, van Heeswijk B, Filho OPS, Tijssen H, Smeets RL, et al. Tnfalpha-Signaling Modulates the Kinase Activity of Human Effector Treg and Regulates IL-17A Expression. Front Immunol (2019) 10:3047. doi: 10.3389/fimmu.2019.03047

36. Urbano PCM, Aguirre-Gamboa R, Ashikov A, van Heeswijk B, KrippnerHeidenreich A, Tijssen H, et al. TNF-Alpha-Induced Protein 3 (TNFAIP3)/ A20 Acts as a Master Switch in TNF-Alpha Blockade-Driven IL-17A Expression. J Allergy Clin Immunol (2018) 142(2):517-29. doi: 10.1016/ j.jaci.2017.11.024

37. Aspalter RM, Eibl MM, Wolf HM. Regulation of TCR-Mediated TCell Activation by TNF-RII. J Leukoc Biol (2003) 74(4):572-82. doi: 10.1189/jlb.0303112

38. Shimizu J, Yamazaki S, Sakaguchi S. Induction of Tumor Immunity by Removing CD25+CD4+ T Cells: A Common Basis Between Tumor Immunity and Autoimmunity. J Immunol (1999) 163(10):5211-8.

39. Ungewickell A, Bhaduri A, Rios E, Reuter J, Lee CS, Mah A, et al. Genomic Analysis of Mycosis Fungoides and Sezary Syndrome Identifies Recurrent Alterations in TNFR2. Nat Genet (2015) 47(9):1056-60. doi: 10.1038/ng.3370

40. Fridman WH, Pages F, Sautes-Fridman C, Galon J. The Immune Contexture in Human Tumours: Impact on Clinical Outcome. Nat Rev Cancer (2012) 12 (4):298-306. doi: 10.1038/nrc3245 
41. Yan F, Du R, Wei F, Zhao H, Yu J, Wang C, et al. Expression of TNFR2 by Regulatory T Cells in Peripheral Blood is Correlated With Clinical Pathology of Lung Cancer Patients. Cancer Immunol Immunother (2015) 64(11):147585. doi: 10.1007/s00262-015-1751-z

42. Gaborit BJ, Chaumette T, Chauveau M, Asquier-Khati A, Roquilly A, Boutoille D, et al. Circulating Treg Cells Expressing TNF Receptor Type 2 Contributes to Sepsis-Induced Immunosuppression in Patients During Sepsis Shock. J Infect Dis (2021) 224(12):2160-9. doi: 10.1093/infdis/jiab276

43. Chou CK, Chen X. Preferential Expansion of CD4(+)Foxp3(+) Regulatory T Cells (Tregs) In Vitro by Tumor Necrosis Factor. Methods Mol Biol (2020) 2111:71-8. doi: 10.1007/978-1-0716-0266-9_6

44. Lubrano di Ricco M, Ronin E, Collares D, Divoux J, Gregoire S, Wajant H, et al. Tumor Necrosis Factor Receptor Family Costimulation Increases Regulatory T-Cell Activation and Function via NF-Kappab. Eur J Immunol (2020) 50(7):972-85. doi: 10.1002/eji.201948393

45. Inoue M, Yamashita K, Tsuji Y, Miki M, Amano S, Okumura T, et al. Characterization of a TNFR2-Selective Agonistic TNF-Alpha Mutant and its Derivatives as an Optimal Regulatory T Cell Expander. J Immunol (2021) 206 (8):1740-51. doi: 10.4049/jimmunol.2000871

46. Okubo Y, Mera T, Wang L, Faustman DL. Homogeneous Expansion of Human T-Regulatory Cells via Tumor Necrosis Factor Receptor 2. Sci Rep (2013) 3:3153. doi: 10.1038/srep03153

47. Padutsch T, Sendetski M, Huber C, Peters N, Pfizenmaier K, Bethea JR, et al. Superior Treg-Expanding Properties of a Novel Dual-Acting Cytokine Fusion Protein. Front Pharmacol (2019) 10:1490. doi: 10.3389/fphar.2019.01490

48. Liang CL, Lu W, Qiu F, Li D, Liu H, Zheng F, et al. Paeoniflorin Ameliorates Murine Lupus Nephritis by Increasing CD4(+)Foxp3(+) Treg Cells via Enhancing Mtnfalpha-TNFR2 Pathway. Biochem Pharmacol (2021) 185:114434. doi: 10.1016/ j.bcp.2021.114434

49. Gao Y, Tang J, Chen W, Li Q, Nie J, Lin F, et al. Inflammation Negatively Regulates FOXP3 and Regulatory T-Cell Function via DBC1. Proc Natl Acad Sci USA (2015) 112(25):E3246-54. doi: 10.1073/pnas.1421463112

50. Valencia X, Stephens G, Goldbach-Mansky R, Wilson M, Shevach EM, Lipsky PE. TNF Downmodulates the Function of Human CD4+CD25hi T-Regulatory Cells. Blood (2006) 108(1):253-61. doi: 10.1182/blood-2005-11-4567

51. Chen X, Subleski JJ, Hamano R, Howard OM, Wiltrout RH, Oppenheim JJ. Co-Expression of TNFR2 and CD25 Identifies More of the Functional CD4 +FOXP3+ Regulatory T Cells in Human Peripheral Blood. Eur J Immunol (2010) 40(4):1099-106. doi: 10.1002/eji.200940022

52. Nunez NG, Tosello Boari J, Ramos RN, Richer W, Cagnard N, Anderfuhren CD, et al. Tumor Invasion in Draining Lymph Nodes is Associated With Treg Accumulation in Breast Cancer Patients. Nat Commun (2020) 11(1):3272. doi: $10.1038 / \mathrm{s} 41467-020-17046-2$

53. Ghods A, Mehdipour F, Shariat M, Talei AR, Ghaderi A. Regulatory T Cells Express Tumor Necrosis Factor Receptor 2 With the Highest Intensity Among CD4(+) T Cells in the Draining Lymph Nodes of Breast Cancer. Mol Immunol (2021) 137:52-6. doi: 10.1016/j.molimm.2021.06.013

54. BI-1808 as a Single Agent and With Pembrolizumab in Treatment of Advanced Malignancies. Available at: https://ClinicalTrials.gov/show/NCT04752826.

55. Mårtensson L, Kovacek M, Holmkvist P, Semmrich M, Svensson C, Blidberg T, et al. 725 Pre-Clinical Development of TNFR2 Ligand-Blocking BI-1808 for Cancer Immunotherapy. J ImmunoTherapy Cancer (2020) 8:A768-8. doi: 10.1136/jitc-2020-SITC2020.0725

56. Boston Immune Technologies and Therapeutics and Beigene Enter Into an Exclusive Option and License Agreement to Develop Novel TNFR2 Antagonists . Available at: https://www.bostonimmunetech.com/media/\#tnf.

57. Krishnan S, Alvarado R, Huang G, Yang X, Filbert EL. Abstract LB175: APX601, a Potent TNFR2 Antagonist as a Novel and Promising Approach to Reverse Tumor Immune Suppression. Cancer Res (2021) 81(13 Supplement): LB175. doi: 10.1158/1538-7445.AM2021-LB175

58. Filbert E, Krishnan S, Alvarado R, Huang G, Bahjat F, Yang X. 693 APX601, a Novel TNFR2 Antagonist Antibody for Cancer Immunotherapy. J ImmunoTher of Cancer (2020) 8(Suppl 3):A417. doi: 10.1136/jitc-2020SITC2020.0693

59. Chen Y, Jia M, Xu S, Zhao Y, Chan E, Zhang M, et al. Abstract 1451: AN3025: A Novel Anti-Human TNFR2 Antibody That Exhibits Immune Activation and Strong Anti-Tumor Activity In Vivo. Cancer Res (2021) 81(13 Supplement):1451. doi: 10.1158/1538-7445.AM2021-1451
60. IND Application for Simcere's Independently Developed Anti-TNFR2 Antibody Accepted by CDE. Available at: https://en.simcere.com/news/detail.aspx?mtt= 170.

61. Available at: http://en.leadsbiolabs.com/R-D-pipeline.htmlhttp://www. leadsbiolabs.com/id41329887.html.

62. Sum CS, Danton M, Pritsker A, Lin R, Yu R, et al. Abstract 1869: Novel TNFR2 Antibodies to Overcome T Cell Exhaustion and Suppressive Tumor Microenvironment. Cancer Res (2021) 81(13 Supplement):1869. doi: 10.1158/ 1538-7445.AM2021-1869

63. Mårtensson L, Cleary K, Semmrich M, Kovacek M, Holmkvist P, Svensson C, et al. Abstract 936: Targeting TNFR2 for Cancer Immunotherapy: Ligand Blocking Depletors Versus Receptor Agonists. Cancer Res (2020) 80(16 Supplement):936. doi: 10.1158/1538-7445.AM2020-936

64. Wei S, Fulton R, Lu Y-Y, Zhang Q, Zhou H, Raue A, et al. Abstract 1883: Mechanism of Action and Biomarker Strategy for HFB200301, an AntiTNFR2 Agonist Antibody for the Treatment of Cancer. Cancer Res (2021) 81 (13 Supplement):1883-3. doi: 10.1158/1538-7445.AM2021-1883

65. Sampson JF, Kurella VB, Paragas V, Kumar S, Lulo JE, Qiu JA, et al. Abstract 555: A Novel Human TNFR2 Antibody (MM-401) Modulates T Cell Responses in Anti-Cancer Immunity. Cancer Res (2019) 79(13 Supplement):555. doi: 10.1158/1538-7445.AM2019-555

66. Richards J, Wong C, Koshkaryev A, Fulton R, Camblin A, Sampson J, et al. Abstract 4846: MM-401, a Novel Anti-TNFR2 Antibody That Induces T Cell Co-Stimulation, Robust Anti-Tumor Activity and Immune Memory. Cancer Res (2019) 79(13 Supplement):4846. doi: 10.1158/1538-7445.AM2019-4846

67. Calzascia T, Pellegrini M, Hall H, Sabbagh L, Ono N, Elford AR, et al. TNFAlpha is Critical for Antitumor But Not Antiviral T Cell Immunity in Mice. $J$ Clin Invest (2007) 117(12):3833-45. doi: 10.1172/JCI32567

68. Zheng L, Fisher G, Miller RE, Peschon J, Lynch DH, Lenardo MJ, et al. Induction of Apoptosis in Mature T Cells by Tumour Necrosis Factor. Nature (1995) 377(6547):348-51. doi: 10.1038/377348a0

69. Ye LL, Wei XS, Zhang M, Niu YR, Zhou Q, et al. The Significance of Tumor Necrosis Factor Receptor Type II in CD8(+) Regulatory T Cells and CD8(+) Effector T Cells. Front Immunol (2018) 9:583. doi: 10.3389/fimmu.2018.00583

70. Li S, Ding J, Wang Y, Wang X, Lv L. CD155/TIGIT Signaling Regulates the Effector Function of Tumor-Infiltrating CD8(+) T Cell by NF-Kappab Pathway in Colorectal Cancer. J Gastroenterol Hepatol (2021) 37(1):154-63. doi: $10.1111 /$ jgh. 15730

71. Tam EM, Fulton RB, Sampson JF, Muda M, Camblin A, Richards J. AntibodyMediated Targeting of TNFR2 Activates CD8(+) T Cells in Mice and Promotes Antitumor Immunity. Sci Transl Med (2019) 11(512):eaax0720. doi: 10.1126/scitranslmed.aax0720

72. Almishri W, Santodomingo-Garzon T, Le T, Stack D, Mody CH, Swain MG. Tnfalpha Augments Cytokine-Induced NK Cell Ifngamma Production Through TNFR2. J Innate Immun (2016) 8(6):617-29. doi: 10.1159/ 000448077

73. Parameswaran N, Patial S. Tumor Necrosis Factor-Alpha Signaling in Macrophages. Crit Rev Eukaryot Gene Expr (2010) 20(2):87-103. doi: 10.1615/CritRevEukarGeneExpr.v20.i2.10

74. Frankenberger C, Rabe D, Bainer R, Sankarasharma D, Chada K, Krausz T, et al. Metastasis Suppressors Regulate the Tumor Microenvironment by Blocking Recruitment of Prometastatic Tumor-Associated Macrophages. Cancer Res (2015) 75(19):4063-73. doi: 10.1158/0008-5472.CAN-14-3394

75. Rossol M, Meusch U, Pierer M, Kaltenhauser S, Hantzschel H, Hauschildt S, et al. Interaction Between Transmembrane TNF and TNFR1/2 Mediates the Activation of Monocytes by Contact With T Cells. J Immunol (2007) 179 (6):4239-48. doi: 10.4049/jimmunol.179.6.4239

76. Fu W, Hu W, Yi YS, Hettinghouse A, Sun G, Bi Y, et al. TNFR2/14-3-3epsilon Signaling Complex Instructs Macrophage Plasticity in Inflammation and Autoimmunity. J Clin Invest (2021) 131(16):e144016. doi: 10.1172/JCI144016

77. Beldi G, Khosravi M, Abdelgawad ME, Salomon BL, Uzan G, Haouas H, et al. Tnfalpha/TNFR2 Signaling Pathway: An Active Immune Checkpoint for Mesenchymal Stem Cell Immunoregulatory Function. Stem Cell Res Ther (2020) 11(1):281. doi: 10.1186/s13287-020-01740-5

78. Beldi G, Bahiraii S, Lezin C, Nouri Barkestani M, Abdelgawad ME, Uzan G, et al. Corrigendum: TNFR2 is a Crucial Hub Controlling Mesenchymal Stem Cell Biological and Functional Properties. Front Cell Dev Biol (2021) 9:753407. doi: $10.3389 /$ fcell.2021.753407 
79. Beldi G, Bahiraii S, Lezin C, Nouri Barkestani M, Abdelgawad ME, Uzan G, et al. TNFR2 is a Crucial Hub Controlling Mesenchymal Stem Cell Biological and Functional Properties. Front Cell Dev Biol (2020) 8:596831. doi: 10.3389/ fcell.2020.596831

80. Ba H, Li B, Li X, Li C, Feng A, Zhu Y, et al. Transmembrane Tumor Necrosis Factor-Alpha Promotes the Recruitment of Mdscs to Tumor Tissue by Upregulating CXCR4 Expression via TNFR2. Int Immunopharmacol (2017) 44:143-52. doi: 10.1016/j.intimp.2016.12.028

81. Hu X, Li B, Li X, Zhao X, Wan L, Lin G, et al. Transmembrane TNF-Alpha Promotes Suppressive Activities of Myeloid-Derived Suppressor Cells via TNFR2. J Immunol (2014) 192(3):1320-31. doi: 10.4049/jimmunol.1203195

82. Yang R, Cai Z, Zhang Y, Yutzy W, Roby KF, Roden RB. CD80 in Immune Suppression by Mouse Ovarian Carcinoma-Associated Gr-1+CD11b+ Myeloid Cells. Cancer Res (2006) 66(13):6807-15. doi: 10.1158/00085472.CAN-05-3755

83. Huang B, Pan PY, Li Q, Sato AI, Levy DE, Bromberg J, et al. Gr-1+CD115+ Immature Myeloid Suppressor Cells Mediate the Development of TumorInduced T Regulatory Cells and T-Cell Anergy in Tumor-Bearing Host. Cancer Res (2006) 66(2):1123-31. doi: 10.1158/0008-5472.CAN-05-1299

84. Gabrilovich DI, Nagaraj S. Myeloid-Derived Suppressor Cells as Regulators of the Immune System. Nat Rev Immunol (2009) 9(3):162-74. doi: 10.1038/nri2506

85. de la Puente P, Muz B, Azab F, Azab AK. Cell Trafficking of Endothelial Progenitor Cells in Tumor Progression. Clin Cancer Res (2013) 19(13):33608. doi: 10.1158/1078-0432.CCR-13-0462

86. Naserian S, Abdelgawad ME, Afshar Bakshloo M, Ha G, Arouche N, Cohen JL, et al. The TNF/TNFR2 Signaling Pathway is a Key Regulatory Factor in Endothelial Progenitor Cell Immunosuppressive Effect. Cell Commun Signal (2020) 18(1):94. doi: 10.1186/s12964-020-00564-3

87. Nouri Barkestani M, Shamdani S, Afshar Bakshloo M, Arouche N, Bambai B, Uzan G, et al. Tnfalpha Priming Through Its Interaction With TNFR2 Enhances Endothelial Progenitor Cell Immunosuppressive Effect: New Hope for Their Widespread Clinical Application. Cell Commun Signal (2021) 19(1):1. doi: 10.1186/s12964-020-00683-x

88. Zhou Q, Wu X, Wang X, Yu Z, Pan T, Li Z, et al. The Reciprocal Interaction Between Tumor Cells and Activated Fibroblasts Mediated by TNF-Alpha/IL33/ST2L Signaling Promotes Gastric Cancer Metastasis. Oncogene (2020) 39 (7):1414-28. doi: 10.1038/s41388-019-1078-x

89. Wang L, Yang D, Tian J, Gao A, Shen Y, Ren X, et al. Tumor Necrosis Factor Receptor 2/AKT and ERK Signaling Pathways Contribute to the Switch From Fibroblasts to Cafs by Progranulin in Microenvironment of Colorectal Cancer. Oncotarget (2017) 8(16):26323-33. doi: 10.18632/oncotarget.15461

90. Torrey H, Butterworth J, Mera T, Okubo Y, Wang L, Baum D, et al. Targeting TNFR2 With Antagonistic Antibodies Inhibits Proliferation of Ovarian
Cancer Cells and Tumor-Associated Tregs. Sci Signal (2017) 10(462): eaaf8608. doi: 10.1126/scisignal.aaf8608

91. Mizoguchi E, Mizoguchi A, Takedatsu H, Cario E, de Jong YP, Ooi CJ, et al. Role of Tumor Necrosis Factor Receptor 2 (TNFR2) in Colonic Epithelial Hyperplasia and Chronic Intestinal Inflammation in Mice. Gastroenterology (2002) 122(1):134-44. doi: 10.1053/gast.2002.30347

92. Heemann C, Kreuz M, Stoller I, Schoof N, von Bonin F, Ziepert M, et al. Circulating Levels of TNF Receptor II are Prognostic for Patients With Peripheral T-Cell Non-Hodgkin Lymphoma. Clin Cancer Res (2012) 18 (13):3637-47. doi: 10.1158/1078-0432.CCR-11-3299

93. Yang M, Tran L, Torrey H, Song Y, Perkins H, Case K, et al. Optimizing TNFR2 Antagonism for Immunotherapy With Tumor Microenvironment Specificity. J Leukoc Biol (2020) 107(6):971-80. doi: 10.1002/JLB.5AB0320415RRRRR

94. Yang D, Li R, Wang H, Wang J, Li Y, Wang H, et al. Clinical Significance of Tumor Necrosis Factor Receptor 2 in Middle and Lower Thoracic Esophageal Squamous Cell Carcinoma. Oncol Lett (2018) 16(3):2971-8. doi: 10.3892/ ol.2018.8998

95. Zhang YW, Chen QQ, Cao J, Xu LQ, Tang X, Wang J, et al. Expression of Tumor Necrosis Factor Receptor 2 in Human Non-Small Cell Lung Cancer and its Role as a Potential Prognostic Biomarker. Thorac Cancer (2019) 10 (3):437-44. doi: 10.1111/1759-7714.12948

96. Nomelini RS, Borges Junior LE, de Lima CA, Chiovato AFC, Micheli DC, Tavares-Murta BM, et al. TNF-R2 in Tumor Microenvironment as Prognostic Factor in Epithelial Ovarian Cancer. Clin Exp Med (2018) 18(4):547-54. doi: 10.1007/s10238-018-0508-3

Conflict of Interest: The authors declare that the research was conducted in the absence of any commercial or financial relationships that could be construed as a potential conflict of interest.

Publisher's Note: All claims expressed in this article are solely those of the authors and do not necessarily represent those of their affiliated organizations, or those of the publisher, the editors and the reviewers. Any product that may be evaluated in this article, or claim that may be made by its manufacturer, is not guaranteed or endorsed by the publisher.

Copyright (C) 2022 Bai, Ding and Li. This is an open-access article distributed under the terms of the Creative Commons Attribution License (CC BY). The use, distribution or reproduction in other forums is permitted, provided the original author(s) and the copyright owner(s) are credited and that the original publication in this journal is cited, in accordance with accepted academic practice. No use, distribution or reproduction is permitted which does not comply with these terms. 